\title{
A New Positive Sign of Functional Weakness in Conversion Disorder: Polysomnography with Extended Surface Electromyography
}

\author{
Jinsub Hwangbo, Mi-Ri Kang, Ki-Hwan Ji \\ Department of Neurology, Busan Paik Hospital, Inje University College of Medicine, Busan, Korea
}

\section{전환장애의 기능위약에 대한 새로운 양성징후: 표면근전도를 이용한 수면다원검사}

황보진섭, 강미리, 지기환

인제대학교 의과대학 부산백병원 신경과학교실

Received November 2, 2020

Revised November 18, 2020

Accepted November 24, 2020

Address for correspondence

Ki-Hwan Ji, MD

Department of Neurology,

Busan Paik Hospital,

Inje University

College of Medicine,

75 Bokji-ro, Busanjin-gu,

Busan 47392, Korea

Tel: +82-51-890-8613

Fax: +82-51-895-6367

E-mail: kihwanji@gmail.com
Patients often present with combinations of psychological disorders that manifest with neurological symptoms and/or signs that are not attributable to identifiable structural or functional etiology associated with the nervous system. We present the case of an elderly woman with functional weakness, which was documented using polysomnography with extended surface electromyography. Our findings show that polysomnography with extended surface electromyography may be a useful diagnostic tool for functional weakness in conversion disorder.

J Sleep Med 2020;17(2):188-191

\section{서 론}

기능위약(functional weakness)은 어떤 신경계질환으로도 일관되거나 합당하게 설명할 수 없는 위약을 칭하며, 심인 또는 비기질마비로 부르기도 한다. 흔히 전환장애나 해리운 동장애의 징후로 나타날 수 있으며, 반신불완전마비(hemiparesis)나 단일불완전마비(monoparesis)가 가장 흔한 형태 이다. ${ }^{1}$ 저자들은 교통사고 후 장기간 왼쪽 팔다리의 반신마 비를 호소하는 기능위약이 의심되는 65세 여성 환자를 경험 하였고, 표면근전도(surface electromyography)를 이용한 수 면다원검사가 진단에 결정적 단서를 제공하였기에 이를 보 고하고자 한다.

This is an Open Access article distributed under the terms of the Creative Commons Attribution Non-Commercial License (https://creativecommons.org/licenses/by-nc/4.0) which permits unrestricted non-commercial use, distribution, and reproduction in any medium, provided the original work is properly cited.

\section{증 례}

65세 여성이 왼쪽 팔다리를 전혀 움직이지 못한다고 하여 병원에 왔다. 환자는 2년 전 버스안에서 승객으로 있다가 교 통사고를 당한 직후에는 증상이 없었고, 약 4개월 후부터 왼 쪽 팔다리위약이 발생하여 증상이 점점 심해졌다고 하였다. 사고 당시 환자는 두부에 타박상을 입으면서 왼쪽 전두엽 부위에 작은 국소출혈이 있었으나 보존 치료 후 퇴원하였다 (Fig. 1). 사고 이후로 환자는 만성두통, 이명, 어지럼증, 우울 증, 불면증을 호소하였다. 다른 병원에서 이미 여러 차례 근 전도 및 뇌 SPECT, 뇌 MRI 검사를 시행하였으나, 왼쪽 팔다 리위약 관련 기질이상은 확인되지 않았다. 본원 정신건강의 학과의 진료와 심리평가에서 경계성지능장애(IQ 70), 경도 치매(clinical dementia rating 1, global deterioration scale 4), 신체증상에 대한 과도한 몰두, 자살사고를 보이는 우울증과 

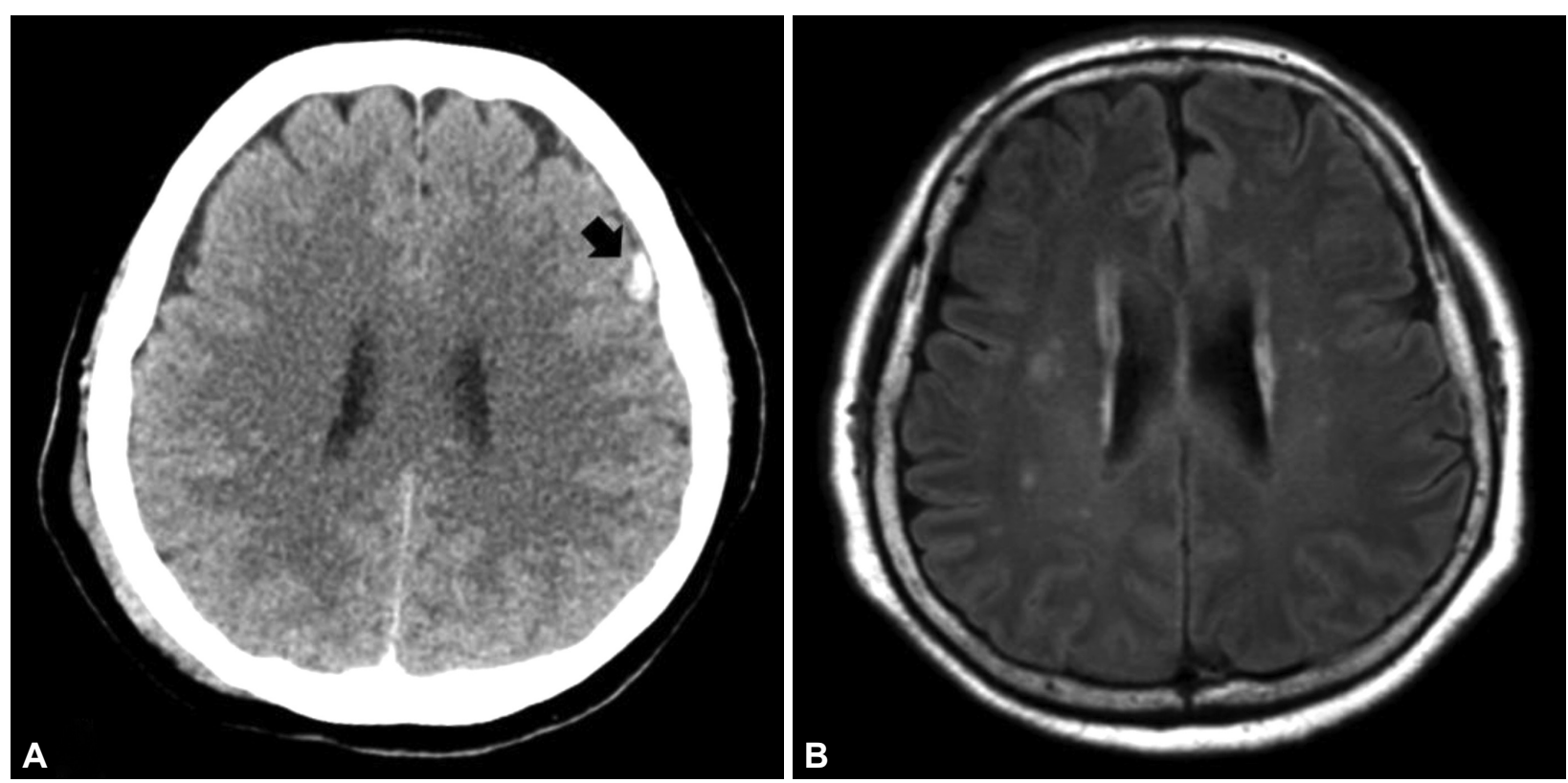

Figure 1. Initial brain CT (A) after a traffic accident and fluid-attenuated inversion recovery image (B) after 2 years. Note a focal hemorrhage (black arrow) in the left frontal lobe.

전환장애에 의한 기능위약으로 잠정 진단을 받은 상태였다. 신경과에는 불면증 및 기능위약에 대한 평가를 위해서 의뢰 되었다. 환자는 보통 저녁 9시에 잠자리에 들지만 잠을 자기 까지 약 1 시간 이상 걸리며, 잠에서도 자주 깨고 다시 잠들기 힘들다고 하였고, 기상 시 두통과 어지럼증을 호소하였다. 코는 약하게 골며, 무호흡은 없다고 하였다. 신경계진찰에서 왼쪽 팔다리의 근력저하[medical research council(MRC) grade 1-2] 및 촉각과 통각저하가 확인되었다. 왼쪽팔다리 위축이나 경직은 없었다. 깊은힘줄반사는 정상이었고 병적 반사는 없었다. 후버징후(Hoover's sign)는 뚜렷하지 않았다. 신경전도검사에서 양쪽 손목의 손목굴증후군(carpal tunnel syndrome) 외 다른 이상은 없었고, 체감각유발전위검사는 정상이었다. 수면상태 및 수면 중 근긴장도를 확인하기 위해 서 수면다원검사를 시행하였다. 검사시 표면근전도 전극을 양쪽 앞정강근(tibialis anterior muscle) 외에 추가로 왼쪽 큰 가슴근(pectoralis major muscle), 위팔노근(brachioradialis muscle), 위팔두갈래근(biceps brachii muscle), 넓적다리곧 은근(rectus femoris muscle)에 부착하였다. 깨어있는 동안 환자에게 왼쪽 팔과 다리를 움직이라고 할 때는 근전도에 근활동이 기록되지 않았다. 하지만 잠이 들고 난 후 환자는 비디오를 통해 양쪽 팔다리의 뚜렷한 움직임(MRC grade 3-4)과 동시에 표면근전도에서 활발한 tonic/phasic activity 가 확인되었다(Fig. 2). 검사는 10시 19분 6시 54분 사이에 시행되었고, 총수면시간은 449분, 수면잠복기 28분, 렘수면 잠복기 166분, 수면효율은 $87.3 \%$ 였다. 입면후각성 (wake after sleep onset)은 8.3\%로 정상범위였다. 총 수면 무호흡지수
는 $13.1 / \mathrm{h}$ 이었고, 렘수면때는 $40.4 / \mathrm{h}$ 까지 증가하였다. 환자 의 불면증 호소와는 달리 정상적인 수면잠복기와 입면후각 성을 보였고, 경증의 수면무호흡 이외 특이점은 확인하지 못 했다. 환자와 보호자에게 검사 결과를 설명한 후 환자는 더 는 병원을 찾지 않았다.

\section{고 찰}

신경과를 방문하는 환자의 약 $1 / 3$ 에서 호소하는 증상이 질 병에 의해서 일부만이 설명되거나 전혀 설명이 되지 않는다. ${ }^{2}$ 신경과의사라면 환자에게 심각한 심인징후가 있는 경우에도 증상을 설명할 수 있는 신경계질환을 배제하려 노력한다. 질 병의 경과를 정기적으로 관찰하는 것이 원인에 대해 가장 큰 정보를 제공해주겠지만, 현실에서 가능하지 않은 경우가 많 고, 가능한 빨리 질병의 객관적인 증거를 얻기 위해 광범위한 검사를 고려하게 된다. 기능마비의 증상 중 편마비나 단일마 비가 가장 흔하나, 심인성비뇌전증발작이나 시각증상, 팔 다 리 위약, 떨림, 이상운동 등 다양한 신경계증상으로 나타나 기도 하며, 진단이 쉽지 않다. ${ }^{1}$ 정신장애진단 및 통계편람 제 5판(Diagnostic and Statistical Manual of Mental Disordersfifth edition, DSM-5)에서는 질병에 의해서 설명되지 않는 마비는 전환장애로 분류하고 있다. 반면 국제질병분류 제 10 개정(International Classification of Disease, version 10)에 서는 해리운동장애로 구분한다. DSM-IV는 전환장애를 더 는 배제진단이 아니라고 규정하며, 신경계진찰에서 양성징 후(positive sign)의 중요성을 강조한다. ${ }^{3}$ 
A

Wake

Pectoralis major muscle, left

Biceps brachii muscle, left

Triceps brachii muscle, left

Brachioradialis muscle, left

Rectus femoris muscle, left

Tibialis anterior muscle, left

Tibialis anterior muscle, right

\section{B}

$\mathrm{N} 2 \rightarrow$ wake

Pectoralis major muscle, left

Biceps brachii muscle, left

Triceps brachii muscle, left

Brachioradialis muscle, left

Rectus femoris muscle, left

Tibialis anterior muscle, left

Tibialis anterior muscle, right

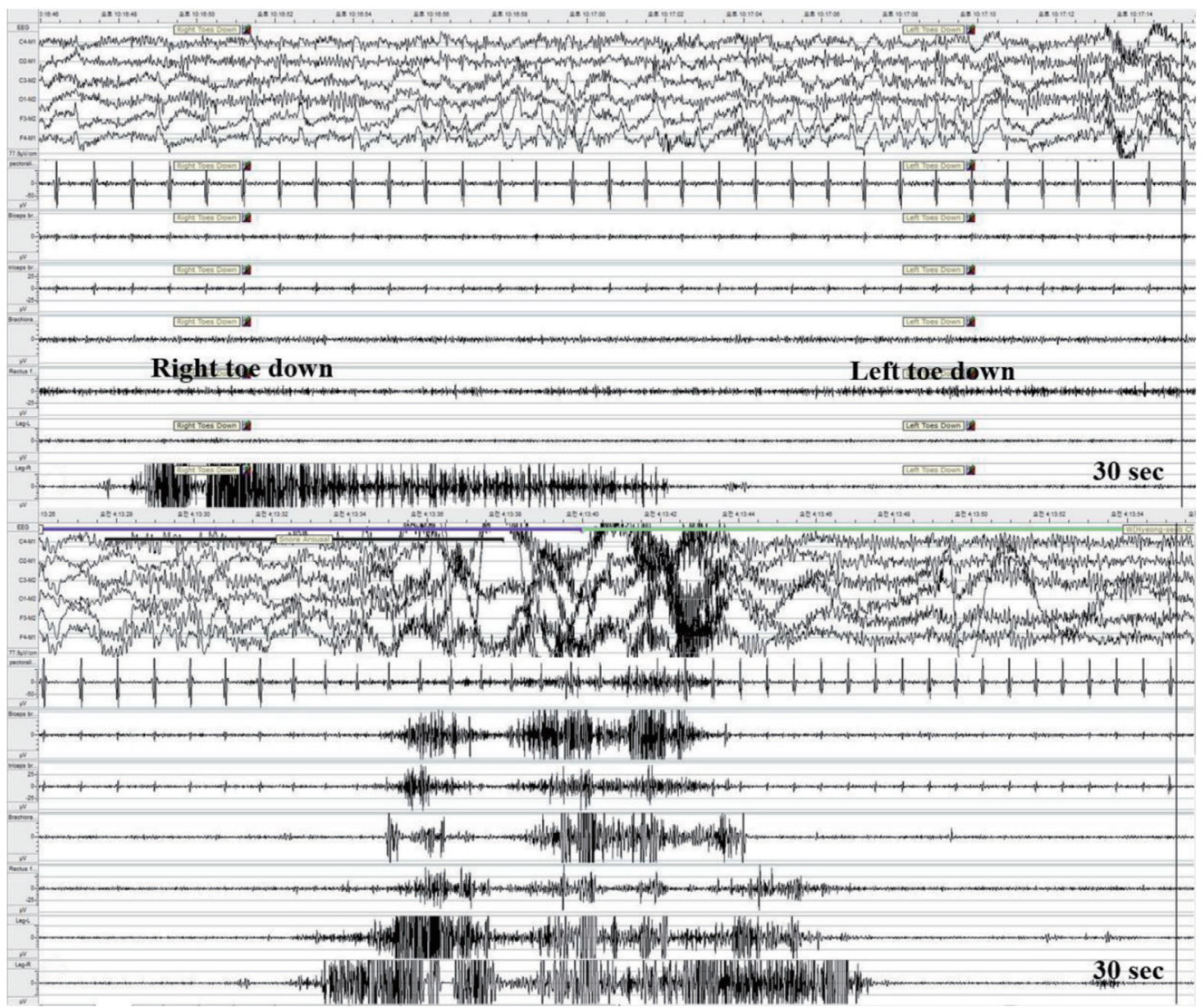

Figure 2. Changes of surface electromyographic activities according to wakefulness and sleep state. While awake, the patient was instructed to move her left arm and leg, but there was no voluntary muscle activity on surface electromyography. Note the increased activity on the right tibialis anterior muscle when she was instructed to move her right toe (A). When the patient slept, increased tonic or phasic activities synchronized with movements under video-monitoring were recorded in the left or bilateral tibialis anterior muscles, and the left upper extremities (B). At that time, the patient raised both arms and bent the left knee. Sensitivity of all surface electromyographic channels was set at $5 \mu \mathrm{V} / \mathrm{mm}$.

환자의 경우 1) 외상 후 증상 발현이 4개월 후에 급작스럽 게 나타난 점, 2) 근력저하 정도가 1 2로 신경계 진찰 때마다 변화가 있었던 점, 3) 근력저하의 정도나 기간에 비해 근위축 이 없는 점, 4) 깊은힘줄반사는 정상, 병적반사는 없었던 점, 5) 구조적인 신경계이상은 확인되지 않은 점, 6) 외상 후 설 명되지 않는 다양한 신체증상을 호소하는 점, 7) 심리평가에 서 우울증과 다양한 신체화장애, 전환장애의 가능성이 높게 고려된 점 등을 고려하면 기능위약의 가능성을 높게 볼 수 있다.

하지만, 전술 한 바와 같이 기능위약을 진단하기 위해서는 임상병력과 증상 등의 상황증거 외에도 신경계검사에서 양 성징후를 확인하는 것이 중요하다. 하지만 다양한 검사법이 개발되어 적용되고 있지만, 모든 환자에게 각각의 검사를 일 괄적으로 적용하기 어렵고, 검사의 민감도(sensitivity)나 특 이도(specificity)가 높지 않고, 검사자 간 해석의 차이가 상당 하여, 결과의 해석에 각별한 주의가 필요하다. ${ }^{4,5}$ 여러 검사법 중 후버징후가 가장 신뢰할만한 증거를 제공한다고 알려져
있다. ${ }^{6}$ 기능위약을 보이는 경우 후버검사(Hoover test)를 통 해 바로 누운자세에서 환자의 근력이 저하된 다리를 들게 하 면 정상 다리에 아래방향의 힘을 주거나, 정상 다리를 검사자 가 누른 상태에서 들어올리라 할 때 환자가 근력이 저하된 다 리에 아래방향의 힘을 주는 경우 후버징후 양성으로 판단하 게 된다. 환자에게는 후버징후가 명확하지 않았으므로, 기능 위약에 대한 뚜렷한 양성징후는 수면다원검사 전까지는 확 인되지 않은 셈이다.

증례의 경우 표준적인 수면다원 검사에서와 같이 앞정강 근에만 양쪽을 부착하여 비교하였고, 그 외에는 환자가 위약 을 호소하는 왼쪽에 근전도를 부착하였다. 따라서 양쪽을 비 교하여 근긴장도를 평가하는 것은 앞정강근에 한하며, 앞정 강근을 제외한 왼쪽 상하지의 경우는 간접적인 비교만이 가 능하다. 전극 개수제한으로 인해 표면근전도를 충분히 부착 하여 검사하지 못한 것은 아쉬운 점이다. 하지만 적외선카메 라를 통해서 수면 중 활발한 왼쪽 팔다리의 움직임을 확인 하였고, 당시 왼쪽 팔근육과 다리근육에서 나타나는 근긴장 
도의 진폭 크기는 오른쪽 앞정강근의 진폭과 비슷했다.

수면다원검사는 편마비 등 기능위약을 의심하는 환자에게 신경계 진찰에서 뚜렷한 양성소견이 나오지 않는 경우 양성 징후를 제공할 수 있는 객관적인 도구로써 임상판단에 도움 을 줄 수 있을 것으로 기대된다. 저자들은 본 증례를 통하여 기능위약이 의심되는 환자에서 표면전극을 추가한 수면다원 검사가 양성징후를 제공하는 유용한 진단의 도구가 될 수 있

다는 것을 제시하는 바이다.

\section{Acknowledgments}

None.

\section{Conflicts of Interest}

The authors have no potential conflicts of interest to disclose.

\section{ORCID iDs}

Jinsub Hwangbo

Mi-Ri Kang

https://orcid.org/0000-0003-4955-0348

Ki-Hwan Ji

https://orcid.org/0000-0002-9833-023X

https://orcid.org/0000-0002-5371-5398

\section{Author Contributions}

Conceptualization: Jinsub Hwangbo. Data curation: Jinsub Hwangbo,
Ki-Hwan Ji. Formal analysis: Jinsub Hwangbo, Mi-Ri Kang. Investigation: Jinsub Hwangbo, Mi-Ri Kang. Methodology: Ki-Hwan Ji. Supervision: KiHwan Ji. Writing_original draft: all authors. Writing_review \& editing: Ki-Hwan Ji.

\section{REFERENCES}

1. Stone J, Sharpe M, Rothwell PM, Warlow CP. The 12 year prognosis of unilateral functional weakness and sensory disturbance. J Neurol Neurosurg Psychiatry 2003;74:591-596. http://dx.doi.org/10.1136/jnnp.74.5.591.

2. Nimnuan C, Hotopf M, Wessely S. Medically unexplained symptoms: an epidemiological study in seven specialities. J Psychosom Res 2001; 51:361-367. https://doi.org/10.1016/S0022-3999(01)00223-9.

3. Stone J, Zeman A, Simonotto E, et al. FMRI in patients with motor conversion symptoms and controls with simulated weakness. Psychosom Med 2007;69:961-969. https://doi.org/10.1097/PSY.0b013e31815b6c14.

4. Daum C, Gheorghita F, Spatola M, et al. Interobserver agreement and validity of bedside 'positive signs' for functional weakness, sensory and gait disorders in conversion disorder: a pilot study. J Neurol Neurosurg Psychiatry 2015;86:425-430. http://dx.doi.org/10.1136/jnnp-2013-307381.

5. Tremolizzo L, Susani E, Riva MA, Cesana G, Ferrarese C, Appollonio I. Positive signs of functional weakness. J Neurol Sci 2014;340:13-18. http://dx.doi.org/10.1016/j.jns.2014.03.003.

6. Stone J, Zeman A, Sharpe M. Functional weakness and sensory disturbance. J Neurol Neurosurg Psychiatry 2002;73:241-245. http://dx.doi. org/10.1136/jnnp.73.3.241. 